\title{
Analysis of Drug-Herb Interaction Frequency in Common Outpatient Medications Using Product Labeling and Drug Information Resources
}

\author{
Rebecca Hoover* and Christopher T Owens \\ Idaho State University, USA
}

Submission: January 14, 2018; Published: March 29, 2018

*Corresponding author: Rebecca Hoover, Director Idaho Drug Information Center Pharmacy Practice and Administration, Idaho State University, USA, Tel: 208-282-2587; Email: hoovrebe@isu.edu

Abstract

Objective: To identify which natural products most frequently interact with commonly dispensed outpatient oral medications per product labelling and drug information resources.

Methods: Recorded drug-herb interactions from 198 outpatient medications were analyzed using the FDA-approved product labelling and the following drug information databases: Clinical Pharmacology, Facts and Comparisons, Lexi-Comp, and Natural Medicines. A list of potentially interacting supplements was compiled according to frequency.

Results: Products interacting with an average more than 5\% of common medications across all resources were St. John's wort (26\%), kava (15\%), and yohimbine (7\%). The non-supplements cannabinoids and grapefruit were also frequently listed in the drug-herb and drugfood interactions (14\% and $11 \%$ respectively). An additional 25 natural supplements had documented interactions with at least $1 \%$ average of included outpatient medications across studied drug information resources.

Conclusion: There are 30 natural products and supplements that have the potential of interacting with at least $1 \%$ of commonly prescribed outpatient oral medications. Health care practitioners should be especially vigilant of patients' use of these supplements as they are the most likely natural products to interaction with common outpatient prescription medications.

Keywords: Natural product; Supplement; Herb; Interaction; Frequency

Abbreviations: CAM: Complementary And Alternative Medicine; FDA: Food and Drug Administration; THC: Tetrahydrocannabinol; NCCIH: National Center for Complementary and Integrative Health

\section{Introduction}

Pharmacognosy, the study of the medicinal uses of plants, served as an early foundation for pharmacy practice. During this time, pharmacists were well aware of benefits and potential drawbacks of many commonly used natural products. As the field of pharmacy practice evolved to include synthetic agents with an increased emphasis on patient care and health care teams, pharmacists shifted their focus away from natural products to the pharmacotherapy of mostly synthetic prescription medications. This led to a compartmentalization between "natural products" and "medications." In current practice, patients and health practitioners may neglect to include herbals, vitamins, and supplements on a current medication list as it has become commonplace to consider these products outside the realm of modern Western medicine [1].
Nevertheless, complementary and alternative medicine (CAM) natural products in the form of vitamins, supplements, and herbal products remain widespread. The Food and Drug Administration (FDA) categorizes natural products as "dietary ingredients" [2]. The term includes vitamins, minerals, herbs/ botanicals, amino acids, enzymes, and organ tissues. These products can come in a variety of forms including tablets, capsules, soft gels, gel caps, liquids, or powders. Surveys document that 15 to 20 percent of adults in the United States use CAM products [3-7]. Since patients are consistently using natural products and supplements, it is essential for health practitioners to be well versed in their safe and efficacious use. As many patients are likely using herbal products alongside prescription medications, it is essential for any health care 
practitioner to add these products in their medication, food, and lifestyle interaction screenings. Drug-herb interactions and their potential harm are well documented [8-10]. There is a need to identify the natural products that are most likely to interact with commonly prescribed outpatient medications.

\section{Objective}

The purpose of this study was to identify the supplements that most frequently interact with commonly prescribed outpatient medications as documented by FDA label information and the following drug information resources: Clinical Pharmacology, Facts and Comparison, Lexi Comp, and Natural Medicines.

\section{Methods}

A list of commonly prescribed outpatient oral medications was developed using a combination of sales and volume statistical data from IMS Health, Drugs.com, and Pharmacy Times drug lists [11-13]. Sublingual or buccal formulations such as sublingual nitro-glycerine were included as oral medications. Suppositories, inhalers, topical formulations, and transdermal patches were excluded due to their potential for inconsistent systemic absorption and therefore lack of consistent documentation for drug-supplement interactions. Injectable drugs were not assessed. Any medications that were also overthe-counter products or had differing salt forms were included.

Oral combination products with each ingredient found independently on the list were excluded to prevent duplication. For example, lisinopril and hydrochlorothiazide were each present on the list which led to the exclusion of the combination product. Otherwise combinations were included such as trimethoprim/sulfamethoxazole and combinations of estrogens and progestin's used in oral contraceptives. Documented drugsupplement interactions were assessed for each medication from five unique drug information resources. These resources were identified as regularly used references in outpatient pharmacy practice. The first resource was the FDA product information accessed through The National Library of Medicine's DailyMed website (https://dailymed.nlm.nih.gov) [14]. All herbal, supplement, and food items listed in the drug interaction section were recorded.
Monographs from three drug databases (Clinical Pharmacology (Elsevier), Facts and Comparisons (Wolters Kluwer) and Lexi Comp (Wolters Kluwer) were also analyzed [15-17]. Interaction sections of individual drug monographs were examined and all herb, supplement, and food items were recorded. The final drug information reference used in the analysis was a specialty database; Natural Medicines (Therapeutic Research Center) [18]. For this database, each medication was selected using the interaction checker. Any herb, supplement, or food items with a "major" interaction rating were recorded.

All data were collected between June and October of 2016. Every natural supplement interaction for each outpatient drug was recorded by three different pharmacists or student pharmacists. If any one of the drug information resources cited an interaction, the interaction was counted. If multiple resources cited an interaction, the interaction was only counted once. Any discrepancies in the list were identified, verified, and remedied by one or more of the study's pharmacists. Using Microsoft Excel, the number of times each herb, supplement, or food item appeared among drug references for each of the oral medications was totalled. The sum was then used to determine the documented potential interaction frequency for each supplement.

\section{Results}

The analysis identified 136 supplements having at least one documented interaction with the 198 prescription medications included in this study using five drug information resources. Of those, 30 supplements interacted with at least two (1\%) of analyzed prescription medications. St. John's wort was the most common supplement to interact with analyzed medications (26\%). Kava, cannabinoids, grapefruit, and yohimbine were additional supplements that interacted frequently with studied outpatient prescription medications (15\%,14\%, 13\%, 7\%). The remaining 25 herbals interacted with an average of less than $5 \%$ of study medications across the drug information references. A listing of the natural products interacting with an average of at least $1 \%$ of analyzed medications as well frequency of interaction documented in at least one reference found in Table 1.

Table 1: Herbs, foods, supplements with average documented interaction frequency greater than or equal to $2 \%$ in commonly prescribed oral outpatient medications.

\begin{tabular}{|c|c|c|}
\hline Natural Product & $\begin{array}{c}\text { Average Interaction Frequency Across All 5 } \\
\text { References }\end{array}$ & $\begin{array}{c}\text { Frequency of Interaction Documented in At } \\
\text { Least One Reference }\end{array}$ \\
\hline St. John's wort/Hypericum perforatum & $26 \%$ & $47 \%$ \\
\hline Kava & $15 \%$ & $30 \%$ \\
\hline $\begin{array}{c}\text { Cannabioids (Cannabidiols, } \\
\text { Tetrahydrocannabinol (THC)) }\end{array}$ & $14 \%$ & $36 \%$ \\
\hline Grapefruit & $13 \%$ & $18 \%$ \\
\hline Yohimbine & $7 \%$ & $20 \%$ \\
\hline Ephedra & $4 \%$ & $16 \%$ \\
\hline Green tea & $4 \%$ & \multicolumn{2}{|c|}{} \\
\hline
\end{tabular}




\section{Global Journal of Pharmacy \& Pharmaceutical Sciences}

\begin{tabular}{|c|c|c|}
\hline Alfalfa & $4 \%$ & $11 \%$ \\
\hline Anise & $4 \%$ & $10 \%$ \\
\hline Bilberry & $4 \%$ & $10 \%$ \\
\hline Red yeast rice & $4 \%$ & $10 \%$ \\
\hline Echinacea & $3 \%$ & $14 \%$ \\
\hline Valerian & $3 \%$ & $14 \%$ \\
\hline Hawthorn & $3 \%$ & $13 \%$ \\
\hline Vitamin E & $3 \%$ & $9 \%$ \\
\hline Caffeine & $2 \%$ & $12 \%$ \\
\hline Guarana & $2 \%$ & $11 \%$ \\
\hline Ginger & $2 \%$ & $10 \%$ \\
\hline Ginkgo & $2 \%$ & $8 \%$ \\
\hline Ascorbic acid/Vitamin C & $2 \%$ & $7 \%$ \\
\hline Garlic & $2 \%$ & $7 \%$ \\
\hline $\begin{array}{l}\text { Grasses (sweet vernal, orchard, perennial rye, } \\
\text { timothy, Kentucky blue, or other unspecified) }\end{array}$ & $2 \%$ & $6 \%$ \\
\hline Digitalis & $1 \%$ & $6 \%$ \\
\hline Syrian rue & $1 \%$ & $6 \%$ \\
\hline Soy/Isoflavones & $1 \%$ & $5 \%$ \\
\hline Feverfew & $1 \%$ & $4 \%$ \\
\hline Ginseng & $1 \%$ & $4 \%$ \\
\hline Bloodroot & $1 \%$ & $3 \%$ \\
\hline Licorice & $1 \%$ & $2 \%$ \\
\hline
\end{tabular}

\section{Discussion}

The results of this study identified the supplements that are most likely to have a documented drug-herb interaction with outpatient prescription medications. St. John's wort topped the list by interacting with twenty-six percent of the medications analyzed. As an inducer of CYP1A2, CYP2C9, and CYP3A4 hepatic metabolism, as well as P-glycoprotein (P-gp) transporter, St. John's wort may interact with a variety of medications [19]. Likewise, the FDA issued a warning regarding kava may be associated with severe hepatic injury [20]. Grapefruit was another common drug-food interaction appearing on the list that might be readily identified by health care practitioners.

However this study also identified supplements that some practitioners may overlook. Marijuana contains cannabinoids and tetrahydrocannabinol (THC) which interact with fourteen percent of studied medications. Patients may be reluctant to disclosure their use of a federally controlled substance. Pharmacist and other health care practitioners need to be proactive in asking about a patient's marijuana use to prevent drug-herb interactions. Yohimbine interacted with an average of seven percent of analyzed outpatient medications. The product has been associated with serious cardiovascular adverse events including myocardial infarction and arrhythmias [21]. The study found there were relatively few supplements that interact with prescription medication. While this list has not identified all drug-herb interactions, the 30 supplements on this list could serve as an education tool or posted reference when conducting drug interaction screenings.

Pharmacists and other health care practitioners should be vigilant on the use of the herbs documented to interact with at least $1 \%$ of outpatient prescription oral medications. Patients should be instructed to develop and maintain a current medication list that includes not only prescription medications but also over-the-counter, vitamin, supplement, and herbal products. The ideal time to identify a possible drug-herb interaction is before the patient begins taking the combination. Being familiar with herbs that are frequently documented with medication interactions may help health practitioners detect particularly worrisome products on a patient's medication list.

This study also sheds light on the variability of drug information resources for natural product interactions. The frequency of interaction increases for each of the 30 identified natural products when only one resource is used to detect and interaction rather than an average frequency across resources. When possible, pharmacists and other health care providers should use multiple drug information resources to determine if a potential drug-herb interaction is possible on a patient's medication list. Limitations of this study included the exclusion of parenteral medications. Medications such as insulin or transdermal patches often appear in the outpatient setting. The study was also restricted to documented drug-herb interactions explicitly stated within product labeling and drug information 
references by name. Some references would list potential groups of herbs that may cause interaction such as "herbs (anticoagulant)," "herbs (hypertensive)," or a certain cytochrome P450 co-enzyme (such as CYP 3A4) inhibitors or inducers. Only natural products explicitly identified by name were included in this analysis.

Other drug information resources such as Review of Natural Products, AltMedDex, American Botanical Council, and National Center for Complementary and Integrative Health (NCCIH) were excluded. Their inclusion may have altered the content or ordering of the developed list. The selection of resources was meant to reflect the resources readily used by dispensing community pharmacists. However, the authors acknowledge other resources may be used by this practicing population. Furthermore, limiting Natural Medicines database's interaction checker to "major" rather than documenting all interactions may have also altered the list's content or ordering. "Minor" or "moderate" interactions may not result in a therapeutic change and some may not require monitoring. The study was further limited by lack of differentiation of how likely an interaction would occur between an herbal product and prescription medication. Some of the interactions documented have occurred may not be common, clinically relevant, or occur in all populations.

\section{Conclusion}

This study identified thirty supplements that have documented interactions with commonly-prescribed oral outpatient medications. Pharmacists and other health care practitioners should have increased alertness when patients are using these supplements. It is essential for practitioners to ensure a patient's complete medication history including natural supplements is up to date, perform a drug-herb interaction check using a variety of drug information resources, and initiate increased monitoring as necessary.

\section{Declaration of Conflicting Interest}

The authors declared the following potential conflicts of interest with respect to the research, authorship, and/ or publication of this article: Dr. Hoover is a consultant for Therapeutic Research Center, the publisher of Natural Medicines Database, and Wolters Kluwer Health, publisher of Lexi-Comp and Facts and Comparisons.

\section{References}

1. Orrico KB (2008) Sources and types of discrepancies between electronic medical records and actual outpatient medication use. J Manag Care Pharm 14(7): 626-631.
2. (2017) US Food and Drug Administration. Dietary supplements guidance documents and regulatory information.

3. Eisenberg DM, Davis RB, Ettner SL, Scott A, Sonja W, et al. (1998) Trends in Alternative medicine use in the United States, 1990-1997: Results of a follow-up national survey. JAMA 280(18): 1569-1575.

4. Eisenberg DM, Kessler RC, Foster C, Norlock FE, Calkins DR, et al. (1993) Unconventional medicine in the United States: Prevalence, costs, and patterns of use. NEJM 328(4): 246-252.

5. Eisenberg DM, Kessler RC, Van Rompay MI, Sonja A, Wilkey, et al. (2001) Perceptions about complementary therapies relative to conventional therapies among adults who use both: Results from a national survey. Ann of Int Med 135(5): 344-351.

6. Kessler RC, Davis RB, Foster DF, Van Rompay MI, Walters EE, et al. (2001) Long-term trends in the use of complementary and alternative medical therapies in the United States. Ann of Int Med 135(4): 262268.

7. Wu CH, Wang CC, Tsai MT, Huang WT, Kennedy J (2014) Trend and pattern of herb and supplement use in the United States: results from the 2002, 2007 and 2012 national health interview surveys. Evid Based Complement Alternat Med 2014: 872320.

8. Wanwimolruk S, Prachayasittikul V (2014) Cytochrome P450 enzyme mediated herbal drug interactions (Part 1). EXCLI J 13: 347-391.

9. Wanwimolruk S, Phopin K, Prachayasittikul V (2014) Cytochrome P450 enzyme mediated herbal drug interactions (Part 2). EXCLI J 13: 869-869.

10. Rao N, Spiller HA, Hodges NL, Chounthirath T, Casavant MJ, et al. (2017) An Increase in Dietary Supplement Exposures Reported to US Poison Control Centers. J Med Toxicol 13(3): 227-237.

11. IMS Health (2013) National Sales Perspectives. Plymouth Meeting, PA: IMS Health US. Pharmaceutical Sales c2000-15.

12. Drugs.com (2013) U.S. Pharmaceutical Sales-2013.

13. Bartholow M (2012) Top 200 Drugs of 2012. Pharmacy Times.

14. Daily Med (2017) National Library of Medicine.

15. (2016) Clinical Pharmacology.

16. (2016) Drug Facts and Comparisons. Facts \& Comparisons e Answers.

17. (2016) Lexi-Drugs Lexicomp. Wolters Kluwer Health Inc, Pennsylvania, USA.

18. (2016) Natural Medicines. Therapeutic Research Center. Stockton, CA, USA.

19. Der Marderosian A, McQueen CE (2012) Potential Drug Interactions with St. John's Wort. Review of Natural Products. Clinical Drug Information, LLC. Philadelphia, PA, USA.

20. Center for Food Safety and Applied Nutrition US Food and Drug Administration (2002) Letter to health care professionals: FDA issues consumer advisory that kava products may be associated with severe liver injury.

21. Kearney T, Tu N, Haller C (2010) Adverse drug events associated with yohimbine-containing products: A retrospective review of the California Poison Control System reported cases. Ann Pharmacother 44(6): 1022-1029. 

CC This work is licensed under Creative Commons Attribution 4.0 License
DOI: 10.19080/GJPPS.2018.05.555662
Your next submission with Juniper Publishers will reach you the below assets

- Quality Editorial service

- Swift Peer Review

- Reprints availability

- E-prints Service

- Manuscript Podcast for convenient understanding

- Global attainment for your research

- Manuscript accessibility in different formats

( Pdf, E-pub, Full Text, Audio)

- Unceasing customer service

Track the below URL for one-step submission https://juniperpublishers.com/online-submission.php 